\title{
The accuracy of nutrition labels as a means of monitoring the reformulation of food in Ireland - The case of yoghurts
}

\author{
S. O’Mahony ${ }^{1,2}$, C. B. O’Donovan ${ }^{1}$, K. McDonald ${ }^{1}$, O. C. Lyons ${ }^{1,3}$, S. F. Quinn ${ }^{1}$, R. J. Creane ${ }^{1}$, \\ M. A. T. Flynn ${ }^{1,3}$, W. Anderson ${ }^{1}$, E. R. Gibney and N. A. Collins ${ }^{1}$ \\ ${ }^{1}$ Food Safety Authority of Ireland, Dublin, Ireland, \\ ${ }^{2}$ University College Dublin, Dublin, Ireland and \\ ${ }^{3}$ Nutrition Innovation Centre for Food and Health, Ulster University, Coleraine, United Kingdom
}

\section{Abstract}

Over half of the Irish population is overweight or obese. The Obesity Policy and Action Plan 2016-2025 will set reformulation targets for fat, saturated fat and sugar in Ireland and review progress. In 2016, the Food Safety Authority of Ireland undertook a crosssectional market scan of yoghurts to evaluate the energy, fat, saturated fat and sugar content based solely on declared nutrition labels. The aims of this 2018 study were to verify the accuracy of declared nutrition information on yoghurts and to confirm the suitability of declared nutrition labels for energy, fat, saturated fat and sugar reformulation monitoring.

Yoghurts identified in the 2016 market scan (n578) were weighted based on categorisation of manufacturer type (branded, own brand), product category (natural, flavoured and luxury) and declared nutrition content. Samples (n200) were randomly selected from these weighted groups and tested by a laboratory accredited for energy, fat, saturated fat, and sugar analysis. Data was analysed using IBM SPSS (version25). As data was not normally distributed, median values were investigated for declared and tested energy, fat, saturated fat and sugar content using Wilcoxon Signed-Rank Test and Spearman Rank-Order Correlation.

Of the tested yoghurts, $3 \%(n 6), 5 \%(n 9)$ and 19\% (n31) were outside the recommended European Commission (EC) labelling tolerance for fat, saturated fat and sugar, respectively. Tested nutrient content was consistently lower than declared. There was a statistically significant difference in declared $v s$. tested energy $(87 \mathrm{kcal} v s .84 \mathrm{kcal} \mathrm{p}=0.03)$, fat $(2.7 \mathrm{~g} v s .2 .5 \mathrm{~g} \mathrm{p}<0.001)$, and sugar $(9.9 \mathrm{~g} v s$. $8.7 \mathrm{~g} \mathrm{p}<0.001)$ content per $100 \mathrm{~g}$ yoghurt. Declared $v s$. tested sugar content per $100 \mathrm{~g}$ yoghurt was statistically significant across all yoghurt types, including natural $(4.8 \mathrm{~g}$ vs. $3.4 \mathrm{~g} \mathrm{p}<0.001)$, flavoured $(9.7 \mathrm{~g}$ vs. $8.6 \mathrm{~g} \mathrm{p}<0.001)$ and luxury $(15 \mathrm{~g} \mathrm{vs.} 13.6 \mathrm{~g} \mathrm{p}=0.002)$. There was a statistically significant difference between declared $v$. tested fat $(2.8 \mathrm{~g} v s .2 .5 \mathrm{~g} \mathrm{p}<0.001)$ and saturated fat $(1.9 \mathrm{~g}$ vs.1.6 g $\mathrm{p}=0.017)$ content of own brand yoghurts per $100 \mathrm{~g}$. There was a positive correlation between energy content and portion size $(\mathrm{r}=.2, \mathrm{p}$ $<0.01)$.

There was a high level of agreement between declared $v s$. tested fat and saturated fat content of yoghurts, but a lower level of agreement between declared $v s$. tested sugar content of yoghurts. This indicates that declared nutrition labels are suitable for reformulation monitoring of fat and saturated fat, but may not be suitable for sugar. This finding will be further investigated and tested in future work planned for nutrition label verification of other food categories.

\section{Conflict of Interest}

There is no conflict of interest. 